\title{
Relationship of Neutrophil Lymphocyte Ratio (NLR) with Parathyroid Hormone (PTH) in Maintenance Hemodialysis Patients
}

\author{
Hazra A. ${ }^{1 *}$, Mandal S. ${ }^{2}$, Chakraborty J. ${ }^{3}$ \\ DOI: https://doi.org/10.17511/jopm.2021.i01.03 \\ 1* Asmita Hazra, Assistant Professor, Department of Biochemistry, Government Medical College, Pali, Rajasthan, India. \\ 2 Saptarshi Mandal, Associate Professor, Department of Transfusion Medicine \& Blood Bank, All India Institute of Medical Sciences, Jodhpur, \\ Rajasthan, India. \\ 3 Jayati Chakraborty, Professor \& Head, Department of Pathology, ESI-PGIMSR, Manicktala, Kolkata, India.
}

Background: Neutrophil-Lymphocyte-Ratio (NLR), a simple derived parameter of routine Complete Blood Counts (CBC), has been shown to be better than WBC count as a marker for inflammation in many contexts. Inflammation is associated with adverse outcomes in hemodialysis patients. Methods: A cross sectional study was designed on 100 maintenance hemodialysis Patients in a tertiary care hospital in Eastern India after IRB permission and informed consent. 88 complete results became available. Complete blood count $(C B C)$, routine PTH and biochemistry analysis were performed. KDIGO 2009 cut offs were used to classify patients by PTH levels (PTH<2ULN, PTH 29ULN \& PTH>9 ULN). NLR was calculated and NLR of 3.5 was used as high inflammation cut off. Results: In Analysis of 88 samples, significant Pearson Correlation with NLR was shown by Albumin, Hemoglobin, PTH, Gender, Age, and Sugar, but involved collinearities. Multiple Linear Regression with Robust estimation of Standard Errors retained only PTH as a significant predictor (Beta= -0.273, $P=0.033$ ) of NLR and Albumin as a borderline significant predictor (Beta $=-0.501, P=$ 0.061). The population was partitioned into 3 sets based on PTH as per KDIGO guideline. Conclusion: Our study suggests that PTH is a significant predictor of inflammation as measured by $N L R$, independent of the other parameters, and it has an overall weak negative association with inflammation especially in the mid-range (PTH 2-9 ULN) subgroup, which largely corroborates with available but scant literature.

Keywords: Hemodialysis (HD), Neutrophil Lymphocyte Ratio (NLR), Parathyroid Hormone (PTH), Inflammation, Multiple Regression

Corresponding Author

Asmita Hazra, Assistant Professor, Department of Biochemistry, Government Medical College, Pali, Rajasthan, India.

Email: hazra.asmita@gmail.com

\section{How to Cite this Article}

Hazra A, Mandal S, Chakraborty J. Relationship of Neutrophil Lymphocyte Ratio (NLR) with Parathyroid Hormone (PTH) in Maintenance Hemodialysis Patients. Trop J Pathol Microbiol. 2021;7(1):17-25. Available From https://pathology.medresearch.in/index.php/jopm/ar ticle/view/510
To Browse

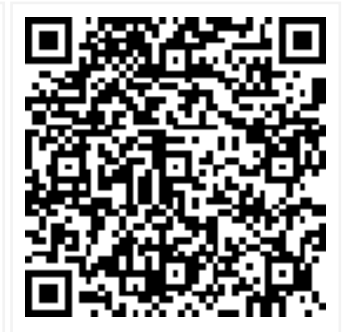

Manuscript Received 2020-12-01

Conflict of Interest No
Review Round 1 2020-12-10

Funding $\mathrm{Nil}$

Review Round 2
2020-12-15
$\begin{gathered}\text { Ethical Approval } \\ \text { Yes }\end{gathered}$

Review Round 2

Yes
Review Round 3

Plagiarism X-checker $6 \%$
Accepted 2021-12-24

Note

(C) 2021 by Asmita Hazra, Saptarshi Mandal, Jayati Chakraborty and Published by Siddharth Health Research and Social Welfare Society. This is an Open Access article licensed under a Creative Commons Attribution 4.0 International License https://creativecommons.org/licenses/by/4.0/ unported [CC BY 4.0]. 


\section{Introduction}

It has been estimated that more than $9.1 \%$ of the World population (697.5 million in 2017) suffer from Chronic Kidney Disease (CKD), including 115.1 million that live in India alone $[1,2]$. In India 1.18 million die of CKD annually [3]. Well over 2 million people are estimated to be receiving life-saving dialysis world-wide, which is only $\sim 10 \%$ of those who need it to survive with CKD Stage 5.[4]. Chronic inflammation is an almost inseparable companion of maintenance hemodialysis (MHD) that in turn is the primary contributor to the cardiovascular mortality risks, malnutrition and the whole spectra of morbidities related to MHD [5]. Inflammation in MHD is still partially understood and multifactorial, including exogenous surface contact activation e.g. dialysis membranes and central venous catheters; in-vivo issues generating at tissue \& cell levels, e.g. oxidative stress and senescence, organ level complications e.g. fluid and sodium overload, poor perfusion \& hypoxia; aggravation by immune $\&$ infectious etiologies e.g. gut dysbiosis and secondary immune maladaptations, and systemic level retention of uremic toxins that include a plethora of molecules including advanced glycation end products, calciprotein particles, indoxyl sulphate and many others [6].

Neutrophil Lymphocyte Ratio (NLR) is the ratio of the neutrophil count and the lymphocyte count in peripheral blood. It is a by-product of a Complete Blood Count (CBC) which is cheap and frequently done to assess anemia, infection or inflammation and many other conditions. NLR, though not new but relatively underused, is a readily available and inexpensive index for inflammation [7]. It is cheaper than other measures of inflammation e.g. CRP, IL6 or ferritin, since NLR has been utilized for prognostication more commonly in the field of oncology and its use in other fields has been relatively rare. It has recently reemerged as an interesting marker associated with various outcomes including all-cause and cardiovascular mortality, [7-9] Heart Failure [10]. etc. It has been shown to be a better predictor of all-cause mortality than TLC (Total Leukocyte ie WBC Count) in these patients [11]. Some studies have tried to evaluate NLR as a surrogate of hsCRP in CKD population [12] but other studies have shown it to be also independently (of hsCRP) associated with endothelial dysfunction and significantly associated with progression of CKD [13].
A study from a leading nephrology group also found that among ratios with lymphocyte in the denominator, it was the only NLR but not PLT (Platelet Lymphocyte Ratio) that provided additional benefit in predicting mortality in addition to demographics, comorbidities and albumin level [8].

CKD eventually leads to a spectrum of Mineral and Bone Diseases (CKD-MBD), including Renal OsteoDystrophy, which in turn range from high bone turnover secondary hyperparathyroidism (SHPT) on one extreme of PTH values to low bone turnover adynamic bone disease [14] on the other extreme. If not treated, increased bone turnover in CKD results in hyperparathyroid bone disease, while overzealous treatment with calcium, calcimimetics etc can lead to too much lowering of PTH, and can be associated with low-turnover adynamic bone disease. PTH is routinely estimated in all hemodialysis patients to monitor CKD-MBD and guide the treatment to keep the PTH in a reasonable middle range. The 2003 Kidney Disease Outcomes Quality Initiative (KDOQI) guideline which recommended PTH to be kept between 130$300 \mathrm{pg} / \mathrm{ml}$, were updated by 2009 "Kidney Disease: Improving Global Outcomes" (KDIGO) guideline which recommend keeping PTH in the range of 2-9 multiples of the upper limit of normal (ULN) of the PTH [15].

Given the high level of PTH in majority of hemodialysis population and the high occurrence of inflammation, PTH has been suspected to have positive association with inflammation in this population. However not many studies have explored relation of PTH with inflammation in the dialysis population and the very few that were published show a rather weak association that changed direction in selecting PTH based subsets, [16] or no association [17]. Studies in an entirely different population: primary hyperparathyroidism and parathyroid adenoma etc. also show inconsistent association of PTH with inflammation [18].

Relationship of PTH to inflammation after hemodialysis population based on PTH based subgroups has been explored by very few studies $[16,19]$ which suggest that paradoxically patients with lower PTH range might be more associated with higher inflammation that patients with higher PTH values.

We decided to study NLR that has not been explored well against PTH in hemodialysis. 
To the best of our knowledge, the only study that tried to perform correlation and multiple regression involving NLR \& PTH in CKD is Toraman et al 2019 [20] which includes a heterogenous mix of 301 patients which includes only 65 lower severity CKD patients and specifically excluded hemodialysis.

\section{Methods}

The study was done after IRB permission and informed consent in a tertiary care hospital in Eastern India. Data of CBC on Sysmex 5-part Autoanalyser and Access2 iPTH CLIA along with routine Biochemistry on samples from 100 consenting patients under maintenance hemodialysis were collected. For Statistical Analysis $\mathrm{R}$ version 3.6.1, Rcmdr and SPSS 23rd Edition were used. NLR was treated as the dependent variable and PTH along with other Biochemistry or hematology parameters (Albumin, Sugar, Hemoglobin) and Age and Gender which showed significant Pearson correlation in initial analysis were tested by Multiple regression. Linear regression using ordinary least square method, with robust estimation of Std. error was applied.

\section{Results}

The final analysis included data from 88 patients (64 Male \& 24 Female) after excluding patients who had incomplete records.

Table 1. Demographic characteristics and laboratory parameters of all patients

\begin{tabular}{|l|l|}
\hline \multicolumn{1}{|c|}{ Parameter } & \multicolumn{1}{|c|}{ Mean \pm SD $(\mathrm{N}=\mathbf{8 8})$} \\
\hline Age $($ Year $)$ & $51.40 \pm 12.52$ \\
\hline Gender $(\mathrm{M}, \%)$ & $73 \%$ \\
\hline White blood cell $(103 / \mu \mathrm{L})$ & $6.73 \pm 1.98$ \\
\hline Neutrophil $(103 / \mu \mathrm{L})$ & $4.67 \pm 1.54$ \\
\hline Lymphocyte $(103 / \mu \mathrm{L})$ & $1.46 \pm 0.55$ \\
\hline Platelet count $(103 / \mu \mathrm{L})$ & $163.25 \pm 74.06$ \\
\hline HGB $(\mathrm{g} / \mathrm{dL})$ & $9.83 \pm 1.80$ \\
\hline NLR & $3.54 \pm 1.52$ \\
\hline Albumin $(\mathrm{g} / \mathrm{dL})$ & $4.25 \pm 0.50$ \\
\hline PTH $(\mathrm{pg} / \mathrm{mL})$ & $450.45 \pm 381.17$ \\
\hline Sugar $(\mathrm{g} / \mathrm{dL})$ & $109.61 \pm 58.01$ \\
\hline
\end{tabular}

Table1: Summary of demographic characteristics and Laboratory parameters of 88 patients who had list wise complete rows of all data required for all analysis. There were 64 males and 24 Females. $\mathrm{HGB}=$ Hemoglobin, NLR=Neutrophil-lymphocyte ratio, $\mathrm{PTH}=$ Parathyroid Hormone.
Table 2. Pearson Correlationc between selected parameters

\begin{tabular}{|c|c|c|c|c|c|c|c|c|}
\hline & & NL & Age & Gender & Sugar & Albumin & HGB & PTH \\
\hline \multirow[t]{3}{*}{ NLR } & Pearson & 1 & .20 & $.233^{*}$ & .134 & $-.294 * *$ & -.252 & -.231 \\
\hline & & & & & & & & \\
\hline & Sig. (2-tailed) & & .06 & .029 & .214 & .005 & .018 & .031 \\
\hline \multirow[t]{3}{*}{ Age } & Pearson & & 1 & .147 & .137 & $-.346 * *$ & -.095 & -.195 \\
\hline & Correlation & & & & & & & \\
\hline & Sig. (2-tailed) & & & .173 & .203 & .001 & .380 & .068 \\
\hline \multirow[t]{3}{*}{ Gender } & Pearson & & & 1 & .070 & $-.233 *$ & -.061 & -.095 \\
\hline & Correlation & & & & & & & \\
\hline & Sig. (2-tailed) & & & & .518 & .029 & .571 & .378 \\
\hline \multirow[t]{3}{*}{ Sugar } & Pearson & & & & 1 & -.141 & -.115 & -.009 \\
\hline & Correlation & & & & & & & \\
\hline & Sig. (2-tailed) & & & & & .190 & .285 & .932 \\
\hline \multirow{3}{*}{$\begin{array}{l}\text { Albumi } \\
\text { n }\end{array}$} & Pearson & & & & & 1 & $.438 *$ & $.245^{*}$ \\
\hline & Correlation & & & & & & * & \\
\hline & Sig. (2-tailed) & & & & & & .000 & .022 \\
\hline \multirow[t]{3}{*}{ HGB } & Pearson & & & & & & 1 & .105 \\
\hline & Correlation & & & & & & & \\
\hline & Sig. (2-tailed) & & & & & & & .330 \\
\hline \multirow[t]{3}{*}{ PTH } & Pearson & & & & & & & 1 \\
\hline & Correlation & & & & & & & \\
\hline & Sig. (2-tailed) & & & & & & & \\
\hline \multicolumn{9}{|c|}{ *. Correlation is significant at the 0.05 level (2-tailed). } \\
\hline \multicolumn{9}{|c|}{ **. Correlation is significant at the 0.01 level (2-tailed). } \\
\hline
\end{tabular}

Apparently significant Pearson Correlations with NLR were shown by Albumin, Hemoglobin, PTH and Gender, whereas Age gave a borderline P value and Sugar did not show enough significance in the final subset. However, as evident from the Pearson Correlation Matrix, the parameters had significant collinearities among themselves. Multiple Linear Regression with Robust estimation of Standard Errors was done. It showed only PTH as a significant negatively related predictor (Beta $=-0.273$, $\mathrm{P}=0.033$ ) of NLR and Albumin as another borderline significant negatively related predictor (Beta= -0.501, $P=0.061$ ). Fitting Age factors into the multiple regression fetched significant (negative) contribution of PTH in NLR, but Age itself has positive but insignificant correlation (Beta 0.057, $P=0.425)$.

Table 3: Multiple Regression with Robust Std. Error Estimation

\begin{tabular}{|l|l|l|l|l|l|l|}
\hline \multirow{2}{*}{ NLR } & \multicolumn{6}{|c|}{ Robust } \\
\cline { 2 - 7 } & Coef. & Std. Err. & $\mathrm{t}$ & $\mathrm{P}>|\mathrm{t}|$ & {$[95 \%$ Conf. } & Interval] \\
\hline In_PTH & -.2726076 & .1256607 & -2.17 & 0.033 & -.5226329 & -.0225823 \\
\hline Albumin & -.5012437 & .2637778 & -1.90 & 0.061 & -1.026079 & .0235914 \\
\hline
\end{tabular}




\begin{tabular}{|l|l|l|l|l|l|l|}
\hline Age & .0578098 & .0720233 & 0.80 & 0.425 & -.085494 & .2011137 \\
\hline Age_sqr & -.0004574 & .0007128 & -0.64 & 0.523 & -.0018756 & .0009609 \\
\hline Gender & .5659255 & .3717526 & 1.52 & 0.132 & -.1737456 & 1.305597 \\
\hline Sugar & .0018746 & .0025078 & 0.75 & 0.457 & -.0031152 & .0068644 \\
\hline cons & 4.903606 & 2.472733 & 1.98 & 0.051 & -.0163559 & 9.823568 \\
\hline
\end{tabular}

Table 3: Dependent variable $=$ NLR (Neutrophil Lymphocyte Ratio). Independent Variables in the final regression model were In_PTH (natural logarithm of PTH), Albumin, Age, Gender and Sugar. Multiple regression using ordinary least square method, with robust estimation of Standard Error, was applied: $\mathrm{N}=88, \mathrm{~F}(4,83)=4.84$, Prob $>\mathrm{F}=$ $0.0015, R 2=0.1644$, Root Mean Square Error: 1.4282. After regression only In_PTH was retained with significant $P$ and Albumin was of borderline significance, and other parameters were not statistically significant.

The population was partitioned into 3 sets based on PTH as per KDIGO guideline. There were 28 Samples with PTH <2ULN, 42 samples with PTH 2-9 ULN, and 18 samples with PTH>9ULN. The negative correlation of the NLR with PTH was corroborated by the Kruskal Wallis $\mathrm{H}$ test across the 3 groups which showed significant difference between the group means $(x 2=6.137, d f=2, P=0.046)$. Partitioning NLR by cut off of NLR>3.5 as high inflammation also fetched a significant Pearson Chi-Square test across the 3 KDIGO PTH groups $(P=0.037)$.

Fig. 1. Distribution of NLR Across 3 groups based on PTH target in KDIGO 2009 Guideline

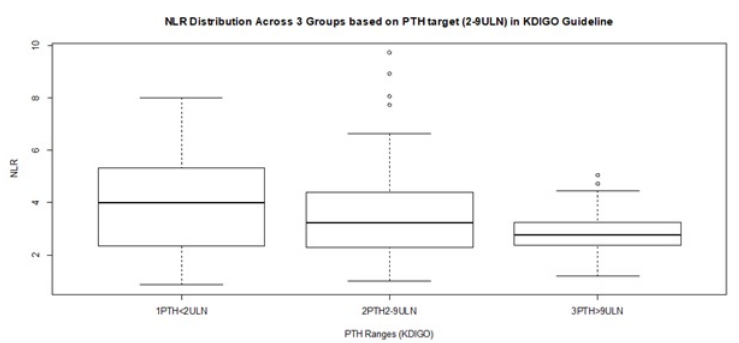

Fig.1: Boxplot output of Rcmdr depicting distribution of NLR Across 3 groups based on PTH target in KDIGO 2009 Guideline. Interquartile range shown as standard box with Median as bold line. Whiskers depicting range after excluding outliers depicted as small circles. Group 1 is PTH below the KDIGO target, Group 2 is within optimal PTH target as per KDIGO and Group 3 is PTH above KDIGO target.

The clear negative correlation of PTH with NLR is apparent in the Box plot. The progressively higher PTH groups have progressively lower mean NLR and also progressively narrower spread of NLR.
The Low PTH group has a higher risk of adynamic bone disorder risk. Whether the higher NLR has any connection with that risk would be worth exploring.

One-way ANOVA of the factor other than PTH (Age, Albumin, Gender, Hemoglobin, Sugar) across the three PTH based KDIGO groups in this sample set did not show significant difference between the group means. One-way ANOVA for Albumin was of borderline significance $(P=0.05)$. While all other parameters did not show significant difference of the 3 group means by Robust ANOVA methods (Welch and Brown-Forsythe) Albumin showed significance (Welch 0.019 and Brown-Forsythe 0.043).

Table 4. ANOVA of the parameters across the 3 groups based on KDIGO PTH targets.

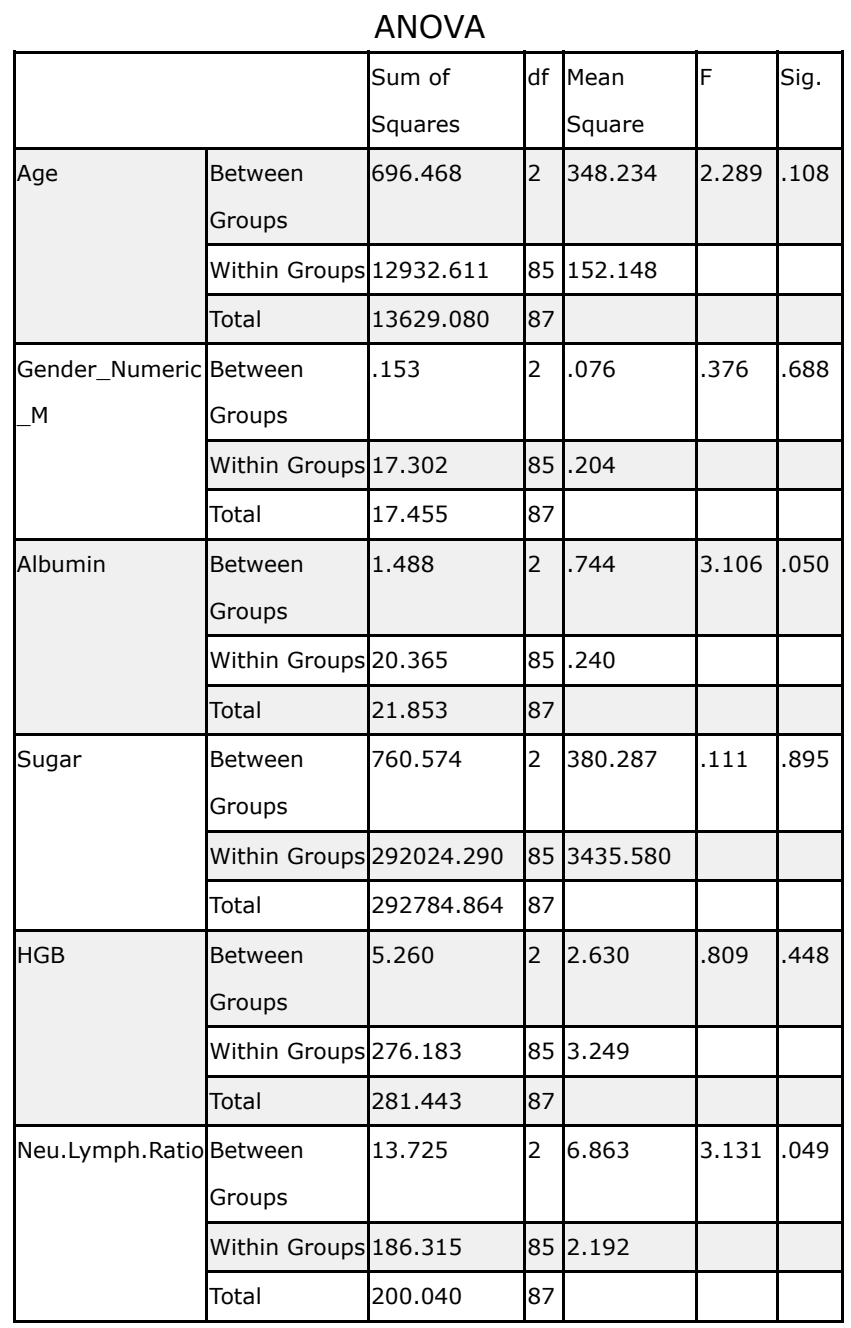

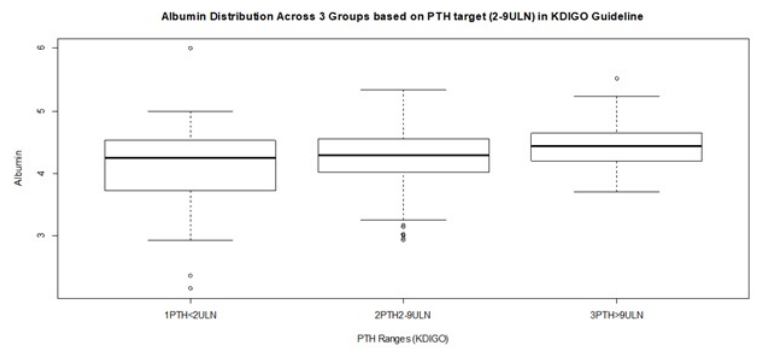


Fig 2. Albumin Distribution across 3 groups based on PTH target in KDIGO 2009 Guideline.

Fig. 2: Boxplot output of Rcmdr depicting distribution of Albumin Across 3 groups based on PTH target in KDIGO 2009 Guideline. Interquartile range shown as standard box with Median as bold line. Whiskers depicting range after excluding outliers depicted as small circles.

\section{Discussion}

In Hemodialysis there is chronic inflammation and PTH is also usually high unless treated. Paradoxically, patients of the low PTH group tend to have more inflammation (high NLR) as shown by Dukkipati et al 2010 as well as our study. Literature is very scant and rather misleading regarding association of PTH with inflammation in general. Very few articles $[21,22,18]$ that claim to explore the relationship of PTH with inflammation in general talk about association of the low-grade inflammation in Primary Hyperparathyroidism and positive correlation with a subset of parameters which are usually weak and mutually not very consistent. A few papers show positive correlation of hsCRP with PTH in inflammatory conditions [23]. However there are also a few recent papers that have shown association of PTH with resolution of inflammation and healing in several contexts e.g. peritonitis [24] and periodontitis $[25,26]$. Low serum PTH level has been shown to be a predictor of infection-associated mortality in incident dialysis patients- both hemodialysis as well as peritoneal dialysis [27]. Our study explores the relationship between the inflammatory marker NLR with PTH as well as Albumin, Age, Gender and Sugar. Here, the NLR showed a weak but significant overall negative relationship to PTH.

To the best of our knowledge, there has not been many studies that have explored the nature of association of PTH with inflammation in hemodialysis patient population. Dukkipati et al 2010 [19] is the first [28] published study to show association of malnutrition-inflammation complex with low serum PTH in CKD patients. RafieianKopaei et al 2012 [16] found a near-significant positive correlation of PTH with CRP in a population of $36 \mathrm{HD}$ patients. They also found that when they deleted the $\mathrm{PTH}<200$ their correlation became positive but statistically insignificant $(r=+0.42$, $\mathrm{P}=.085)$ but when they deleted the PTH $>500$ it turned significantly negative $(r=-0.42, P=0.04)$. Our study corroborates with these findings.
Jaqueto et al 2016 [17] published data from 132 hemodialysis patients which explored relationship of PTH with inflammatory mediators IL- 1, IL- 6 and TNF-a, and found no association. Their analysis included Spearman Correlation (PTH as continuous variable) and Kruskal wallis test (PTH divided into tertiles with cut off at 198 and 517) but no multiple regression.

In multiple regression analysis, PTH levels in hemodialysis in our study came out as a more significant determinant of NLR as compared to Albumin, Age, Gender and Sugar. Toraman et al. 2019 [20] exploring the relationship of NLR and PTH includes a heterogenous population of 301 patients which includes only 65 CKD patients, and specifically excluded severe CKD with hemodialysis. They performed multiple regression and found only a very small contribution of PTH ( $\beta=-.001)$ to NLR, and a bigger contribution from Gender, Albumin, LDL and Hemoglobin. Not only is their patient population fundamentally different from our study, there is also an opposite skew in the gender distribution- $73 \%$ males in our study vs $14 \%$ Males in Toraman et al [20].

Parathyroid hormone is expected to have a deep relation with immune system [29] due to myriad reasons, including presence of PTH receptors on most immune cells including Neutrophils and lymphocytes, [30] PTH regulating action of vitamin D which is a major immune modulator, and also PTH directly regulates Calcium which is involved in most immune signaling. However, the majority of the previous research have mostly focused on one extreme where PTH is very high and there is apparently "high inflammation", but also there is an acquired immune dysfunction and the situation is majorly confounded by presence of many other uremic toxins. Whether the PTH is an aggravating factor or a compensatory factor that prevents the inflammation from further aggravation is not yet clear.

Not only does our finding of a negative correlation of PTH with NLR corroborate with Dukkipati 2010, [19] Feroze 2011,[28] Rafieian-Kopaei [16] this is also mechanistically viable. There has now been gradually emerging in-vitro (cell/organ culture) and animal data that show mutual inhibitory effects of parathyroid gland/PTH and inflammatory cells/mediators [31-34]. Neilson et al 1997 [32] showed that IL-1b suppressed PTH release from bovine parathyroid organ culture, by upregulating Calcium Sensing Receptor (CaSR) expression. 
The effect was shown only in intact PTH gland ex vivo, not dissociated cells, and was neutralized by the specific inhibitor IL1Ra. CaSR the main feedback regulator of PTH secretion, is itself also directly involved in anti-inflammatory and anti-tumorigeic signaling in organs other than Parathyroid and Kidney, e.g. intestines [34].

Mouse and Rat in vivo inflammation models as early as 1991-92 [31,35] had shown that recombinant PTH agonist fragment $1-34$ has direct antiinflammatory effect tested both in paw croton oil injection and several other drug induced inflammation models, mast cell histamine release assays etc. In a recent study, McCauley et al. 2014 [33] show that injection of PTH stimulates secretion of anti-inflammatory mediators, or more specifically Specialized pro-resolving mediators (SMP) e.g. Resolvin D1 and D2, Protectin D1 etc in murine spleen and bone marrow, and synergizes in dead cell clearing activity (efferocytosis) by macrophages which is a part of inflammation resolving process. The recruitment of mesenchymal stem cells and local amplification of anti-inflammatory action by various mediators including TGF-b were also thought to be contributory phenomena. These together potentially explains the negative relationship between PTH and inflammation.

Age, Gender, Sugar etc. apparently did not seem to retain significance in this regression model. Whether all these are chance associations (or lack thereof) or due to some confounder or due to some real mechanistic causality (and its direction) cannot be concluded from the present study and needs to be replicated and discerned in further studies.

Among the 3 KDIGO based PTH subgroups, the middle subgroup i.e. the patients with optimal control of PTH had the largest numbers ( $48 \%$ ) and showed negative correlation with NLR. However, the relationship of PTH to NLR was not uniform across subgroups. In the subgroups with suboptimal PTH (especially in the extremes), NLR seemed to have apparently positive (rather than negative) relation with PTH, none of which were statistically significant in this sample. These might need further study with greater focus on hemodialysis subsets with extreme PTH values.

The PTH measurement in hemodialysis is fraught with the accumulation of the long-lived C-terminal fragments of PTH as compared to very small proportion of the short lived bio-intact PTH.
However, the so called inactive C-terminal fragments that accumulate in hemodialysis are not truly inactive and very little is known about their mechanism of action. There is now emerging new data that show that these fragments may play complex interesting roles. Similar $\mathrm{C}$ terminal fragment of the related PTH related peptide also has anti-inflammatory and anti-senescence activities [36].

\section{Conclusion}

In conclusion, our study suggests that PTH is a significant predictor of inflammation independent of the other parameters.

\section{What does the study add to the existing knowledge?}

PTH has an overall weak negative association with inflammation especially in the mid-range (PTH 2-9 ULN) subgroup.

\section{Author's contribution}

Dr. Asmita Hazra: Concept, study design

Dr. Saptarshi Mandal: Manuscript preparation

Dr. Jayati Chakraborty: Manuscript preparation

\section{Reference}

01. Levin A, Tonelli M, Bonventre J, Coresh J, Donner JA, et al. Global kidney health 2017 and beyond- A roadmap for closing gaps in care, research, and policy. Lancet (London, England. 390(10105); 1888-1917.

doi: $10.1016 / \mathrm{S0140-6736(17)30788-2 \quad \text {[Crossref] }}$

02. Bikbov B, Purcell C A, Levey A S, Smith $M$, Abdoli $A$, Abebe $M$, et al. Global, regional, and national burden of chronic kidney disease, 1990-2017- A systematic analysis for the Global Burden of Disease Study 2017. The Lancet. 395(10225)709-733.

doi: $10.1016 / \mathrm{S} 0140-6736(20) 30045-3 \quad$ [Crossref]

03. Bharati J, Jha V (2020). Global Dialysis Perspective- India. Kidney. 360;1(10)11431147.

doi: $10.34067 /$ KID. 0003982020 [Crossref] 
04. Couser W G, Remuzzi G, Mendis S, Tonelli M. The contribution of chronic kidney disease to the global burden of major noncommunicable diseases. Kidney International. 2011;80(12)1258-1270.

[Crossref]

05. Achinger S G, Ayus J C. Inflammation from dialysis, can it be removed?. Nephrology Dialysis Transplantation. 2013;28(4)770-773. doi: $10.1093 / \mathrm{ndt} / \mathrm{gfs} 480 \quad$ [Crossref]

06. Cobo G, Lindholm B, Stenvinkel P. Chronic inflammation in end-stage renal disease and dialysis. Nephrology Dialysis Transplantation, 2018;33(Suppl 3)iii35-iii40. doi: 10. 1093/ndt/gfy175 [Crossref]

07. Li H, Lu X, Xiong R, Wang S. High neutrophil-tolymphocyte ratio predicts cardiovascular mortality in chronic hemodialysis patients. Mediators of Inflammation. 2017.

[Crossref]

08. Catabay C, Obi Y, Streja E, Soohoo M, Park C, Rhee CM, Kovesdy C P, Hamano T, KalantarZadeh K. Lymphocyte Cell Ratios and Mortality among Incident Hemodialysis Patients. American Journal of Nephrology. 2017;46(5)408-416.

doi: $10.1159 / 000484177$ [Crossref]

09. Zhao WM, Tao SM, Liu GL. Neutrophil-tolymphocyte ratio in relation to the risk of allcause mortality and cardiovascular events in patients with chronic kidney disease- A systematic review and meta-analysis. Renal Failure. 2020;42(1)1059-1066.

doi: $10.1080 / 0886022 \times .2020 .1832521$ [Crossref]

10. Li $X$, Zhang $X$, Yang $Y$, Du L, Zhang J, Zhang $Y$, Wang $C$. Increased neutrophil/leukocyte ratio of the peripheral blood in chronic heart failure patients with renal dysfunction. INTERNATIONAL JOURNAL OF CLINICAL AND EXPERIMENTAL MEDICINE. 2019;12(5)5951-5959.

[Crossref]

11. Ouellet G, Malhotra R, Penne E L, Usvya L, Levin N W, Kotanko P. Neutrophil-lymphocyte ratio as a novel predictor of survival in chronic hemodialysis patients. Clinical Nephrology. 2016;85(4)191-198.

[Crossref]
12. Malhotra R, Marcelli D, von Gersdorff G, Grassmann A, Schaller M, Bayh I, Scatizzi L, Etter M, Guinsburg A, Barth C. Relationship of neutrophil-to-lymphocyte ratio and serum albumin levels with C-reactive protein in hemodialysis patients- Results from 2 international cohort studies. Nephron. 2015;130(4)263-270.

[Crossref]

13. Solak Y, Yilmaz M I, Sonmez A, Saglam M, Cakir E, Unal H U. Neutrophil to lymphocyte ratio independently predicts cardiovascular events in patients with chronic kidney disease. Clinical and Experimental Nephrology. 2013;17(4)53240. doi: 10.1007/s10157-012-0728-x [Crossref]

14. Moe S M. Definition and classification of renal osteodystrophy and chronic kidney diseasemineral bone disorder (CKD-MBD), In The Spectrum of Mineral and Bone Disorders in Chronic Kidney Disease. Oxford University Press. Retrieved January 12, 2021.

[Article] [Crossref]

15. Cavalier E, Carlisi A, Bekaert AC, Rousselle O, Chapelle JP, Delanaye P. New insights on the stability of the parathyroid hormone as assayed by an automated 3rd generation PTH assay. Clinica Chimica Acta- International Journal of Clinical Chemistry. 2012;413(1-2)353-354. doi: 10.1016/j.cca.2011.09.034 [Crossref]

16. Rafieian-Kopaei M, Baradaran A, Nasri H. Association of secondary hyperparathyroidism with malnutrition and inflammation in maintenance hemodialysis patients. Life Science Journal. 2012;9(3)1871-1878.

[Crossref]

17. Jaqueto $M$, Delfino $V$ D A, Bortolasci $C C$, Barbosa D S, Morimoto H K, Frange R F N, et al. Are PTH levels related to oxidative stress and inflammation in chronic kidney disease patients on hemodialysis?. Brazilian Journal of Nephrology. 2016;38(3)288-295.

doi: 10.5935/0101-2800.20160045 [Crossref]

18. Christensen M H E, Fenne I S, Nordbø $Y$, Varhaug J E, Nygård K O, Lien E A, Mellgren G. Novel inflammatory biomarkers in primary hyperparathyroidism. European Journal of Endocrinology. 2015;173(1)9-17.

doi: 10.1530/EJE-14-1038 [Crossref] 
19. Dukkipati R, Kovesdy C P, Colman S, Budoff $M J$, Nissenson A R, Sprague S M, Kopple J D, Kalantar-Zadeh K. Association of relatively low serum parathyroid hormone with malnutritioninflammation complex and survival in maintenance hemodialysis patients. Journal of Renal Nutrition. $2010 ; 20(4) 243-254$.

doi: $10.1053 /$ j.jrn.2009.10.006 [Crossref]

20. Toraman A, Aras F, Hekimsoy Z, Kursat S. IS THERE A RELATIONSHIP BETWEEN PARATHYROID HORMONE AND NEUTROPHIL LYMPHOCYTE RATIO OR PLATELET LYMPHOCYTE RATIO?. Acta Endocrinologica (Bucharest). 2019;15(1)96-101.

doi: 10.4183/aeb.2019.96 [Crossref]

21. Emam A A, Mousa S G, Ahmed K Y, Al-Azab A A. Inflammatory Biomarkers in Patients with Asymptomatic Primary Hyperparathyroidism. Medical Principles and Practice. 2012;21(3)249253.

doi: $10.1159 / 000334588$ [Crossref]

22. Cheng SP, Liu CL, Liu TP, Hsu YC, Lee JJ. Association between parathyroid hormone levels and inflammatory markers among US adults. Mediators of Inflammation. 2014;709024.

doi: $10.1155 / 2014 / 709024$ [Crossref]

23. Venkatesan $S$, Chakkarai $K$, Arulvijayavani $S$, Senthilkumar G P, Manikandan R, Kalyaperumal M. Association between vitamin $D$, parathyroid hormone and inflammatory markers in urolithiasis patients. Journal of Renal Injury Prevention. 2017;6(4)240-243.

doi: $10.15171 /$ jrip.2017.45 [Crossref]

24. Yang Y, Da J, Yi J, Yuan J, Zha Y. Low serum parathyroid hormone is a risk factor for peritonitis episodes in incident peritoneal dialysis patients- A retrospective study. BMC Nephrol. 2020.

doi: $10.21203 /$ rs.3.rs-55536/v2 [Crossref]

25. Otawa M, Tanoue R, Kido $H$, Sawa $Y$, Yamashita J. Intermittent administration of parathyroid hormone ameliorates periapical lesions in mice. Journal of Endodontics. 2015;41(5)646-651. doi: $10.1016 /$ j.joen.2014.12.008 [Crossref]
26. Stutz C, Batool F, Petit C, Strub M, Kuchler-Bopp $S$, Benkirane-Jessel $N$, Huck O. Influence of parathyroid hormone on periodontal healing in animal models- A systematic review. Archives of Oral Biology. 2020;120;104932.

doi: 10.1016/j.archoralbio.2020.104932 [Crossref]

27. Hong $Y$ A, Kim J H, Kim $Y$ K, Chang $Y$ K, Park $C$ W, Kim S Y, et al. Low parathyroid hormone level predicts infection-related mortality in incident dialysis patients- A prospective cohort study. The Korean Journal of Internal Medicine. 2020;35(1)160-170.

doi: $10.3904 / \mathrm{kjim} .2018 .264$ [Crossref]

28. Feroze $U$, Molnar M Z, Dukkipati R, Kovesdy C $P$, Kalantar-Zadeh $\mathrm{K}$. Insights Into Nutritional and Inflammatory Aspects of Low Parathyroid Hormone in Dialysis Patients. Journal of Renal Nutrition. $2011 ; 21(1) 100-104$.

doi: $10.1053 / j . j r n .2010 .10 .006$ [Crossref]

29. Geara A S, Castellanos M R, Bassil C, SchullerLevis G, Park E, Smith M, Goldman M, Elsayegh $S$. Effects of Parathyroid Hormone on Immune Function. Clinical and Developmental Immunology. 2010.

doi: 10.1155/2010/418695 [Crossref]

30. Perry H M, Chappel J C, Bellorin-Font E, Tamao J, Martin K J, Teitelbaum S L. Parathyroid hormone receptors in circulating human mononuclear leukocytes. The Journal of Biological Chemistry. 1984;259(9)5531-5535. [Crossref]

31. Clementi G, Caruso A, Cutuli V, Prato A, Fiore C E, Amico-Roxas M. Parathyroid hormone fragment 1-34 and anti-inflammatory effect. Archives Internationales De Pharmacodynamie Et De Therapie. 1992;315;87-95. [Crossref]

32. Nielsen P K, Rasmussen AAK, Butters R, FeldtRasmussen $U$, Bendtzen K, Diaz R, Brown Em, Olgaard $K$. Inhibition of PTH Secretion by Interleukin-1 $\beta$ in Bovine Parathyroid Glandsin VitroIs Associated with an Up-Regulation of the Calcium-Sensing Receptor mRNA. Biochemical and Biophysical Research Communications. 1997;238(3)880-885.

doi: $10.1006 /$ bbrc.1997.7207 [Crossref] 
33. McCauley L K, Dalli J, Koh A J, Chiang N, Serhan C N. Cutting edge- Parathyroid hormone facilitates macrophage efferocytosis in bone marrow via proresolving mediators resolvin D1 and resolvin D2. Journal of Immunology (Baltimore, Md-1950). 2014;193(1)26-29.

doi: $10.4049 /$ jimmunol.1301945 [Crossref]

34. Iamartino L, Elajnaf T, Kallay E, Schepelmann M. Calcium-sensing receptor in colorectal inflammation and cancer- Current insights and future perspectives. World Journal of Gastroenterology. 2018;24(36)4119-4131. doi: $10.3748 /$ wjg.v24.i36.4119 [Crossref]
35. Caruso A, Amico-Roxas M, Cutuli V, Prato A, Fiore $C$ E, Clementi $G$. Parathyroid hormone fragment 1-34 inhibits drug-induced inflammation in various experimental models. European Journal of Pharmacology 1991;198(1)85-88. doi: 10. 1016/0014-2999(91)90565-8 [Crossref]

36. Platas J, Guillén M I, Gomar F, Castejón M A, Esbrit $P$, Alcaraz M J. Anti-senescence and Antiinflammatory Effects of the C-terminal Moiety of PTHrP Peptides in OA Osteoblasts. The Journals of Gerontology- Series A. 2017;72(5)624-631. doi: $10.1093 /$ gerona/glw100 [Crossref] 